\title{
Sir William Withey Gull (1816-1890)
}

\author{
J.M.S. Pearce \\ Emeritus Consultant Neurologist, Department of Neurology, Hull Royal Infirmary, Hull, UK
}

\section{Key Words}

William Gull · Myxoedema · Anorexia nervosa •

Paraplegia $\cdot$ Conspiracy theories

\begin{abstract}
William Gull, a man of humble origins, became one of the outstanding, polymath physicians of the 19th century, and physician to Queen Victoria. Among several important and original contributions, this paper summarises his work on myxoedema, paraplegia and anorexia nervosa.
\end{abstract}

Copyright $\odot 2006$ S. Karger AG, Basel

Contrary to ominous but unfounded personal rumours (vide infra), William Gull, (fig. 1.) a man of humble beginnings, became one of the outstanding, polymath physicians of the 19th century. His celebrated success in practice was largely due to minute attention to detail, and to his unremitting, devoted care of his patients [1]. This paper attempts a brief depiction of a selection of his major contributions, particularly on myxoedema, and those related to the nervous system.

Gull was born at Colchester, in the parish of St. Leonard's, on December 31st, 1816. His father, a barge owner on the River Lea, was a tenant of Guy's Hospital, who received from the treasurer, Mr. Benjamin Harrison, a presentation for his son to attend Christ's Hospital. After

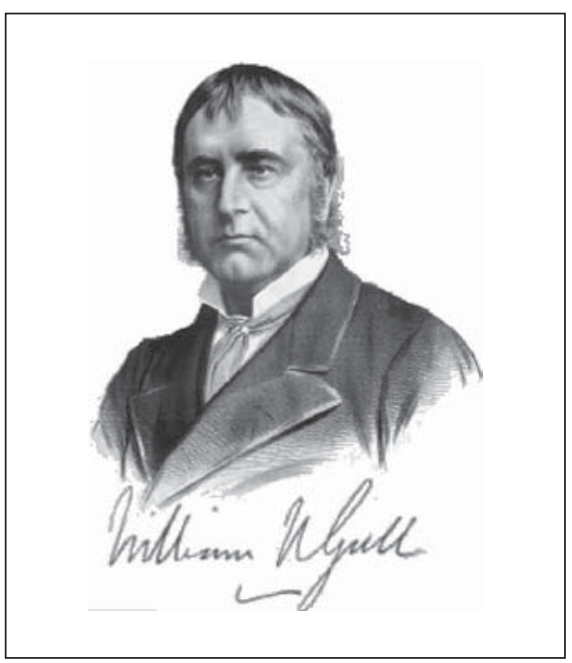

Fig. 1. Sir William Withey Gull.

completing his education there, William Gull took an engagement as an usher in a school at Lewes; while so employed, he prepared a new catalogue for the Guy's Hospital Museum. The treasurer thought well of young Gull, and offered him this position. Soon afterwards, Gull decided on a career in Medicine. He entered Guy's in 1837. A zealous and distinguished medical student [2], he graduated in 1841 and received the MD with gold medal in 1846. He taught natural philosophy, comparative anatomy and physiology at Guy's from 1846 to 1856 and was

\section{KARGER}

Fax +4161306 1234 E-Mail karger@karger.ch www.karger.com
(C) 2006 S. Karger AG, Basel 0014-3022/06/0551-0053\$23.50/0

Accessible online at:

www.karger.com/ene
J.M.S. Pearce

304 Beverley Road

Anlaby, East Yorks HU10 7BG (UK) 
then appointed physician, serving as consulting physician until retirement. Gull produced several works relevant to the practice of neurology, notably on myxoedema, anorexia nervosa, and paraplegia.

\section{Myxoedema}

At the time of Claude Bernard's introduction of the term 'internal secretion' in 1855 , and his concept of the milieu intérieur, Moritz Schiff (1823-1896) of Frankfurt am Main, while working in Berne in 1859, showed that thyroidectomy in dogs invariably proved fatal; and he later showed that grafts or injections of thyroid reversed the symptoms in both thyroidectomised animals and humans. He thought the thyroid liberated some important substance into the blood. Gull in 1873 was one of the first to understand that the cause of myxoedema is atrophy of the thyroid gland. Three years earlier, Charles Hilton Fagge, also of Guy's, wrote a paper on 'sporadic cretinism'.

Gull's seminal paper [3] related the symptoms and changed appearance of a Miss B:

\footnotetext{
'After the cessation of the catamenial period, became insensibly more and more languid, with general increase of bulk ... Her face altering from oval to round ... the tongue broad and thick, voice guttural, and the pronunciation as if the tongue were too large for the mouth (cretinoid) ... In the cretinoid condition in adults which I have seen, the thyroid was not enlarged ... There had been a distinct change in the mental state. The mind, which had previously been active and inquisitive, assumed a gentle, placid indifference, corresponding to the muscular languor, but the intellect was unimpaired ... The change in the skin is remarkable. The texture being peculiarly smooth and fine, and the complexion fair, at a first hasty glance there might be supposed to be a general slight oedema of it ... The beautiful delicate rose-purple tint on the cheek is entirely different from what one sees in the bloated face of renal anasarca.'
}

In 1888, W.M. Ord [4] introduced the term myxoedema. The Nobel Prize winner, Emil Theodor Kocher of Berne, had noticed symptoms like adult cretinism developed gradually after thyroidectomy (16 of his 100 cases reported in 1883), which he had pioneered. He also observed that 'Surgeons had simply assumed that the thyroid gland has no function whatever ...'. Jacques-Louis Reverdin confirmed this ignorance by asking in 1882 , 'Can it be that the thyroid body whose functions are still obscure plays a part in haematopoiesis so important that its ablation produces such profound trouble?'

George Redmayne Murray of Newcastle, stimulated by his mentor Victor Horsley (who had induced signs of myxoedema in monkeys by removing their thyroids) in- troduced in Britain ${ }^{1}$ its successful treatment with injections of sheep thyroid extract [6].

William Smith Greenfield of Edinburgh who examined pathologically one of Ord's myxoedema cases observed it was the antithesis to exophthalmic goitre. He also highlighted and refuted the concept then current: that Graves' disease was primarily a disorder of the nervous system. In his Bradshaw Lecture (1893) he said:

'In thus discussing Graves' disease, even provisionally as a disease of the thyroid gland rather than of the nervous system, I am aware that I am opposed to nearly all English and American physicians of eminence.'

Gull (with H.G. Sutton in 1872) turned his attention to the arterio-capillary fibrosis in chronic nephritis that may be the first account of renovascular hypertension [7], clarified in 1934 by Harry Goldblatt. In 1862 came an early description of syringomyelia [8], and four years later he clarified the pathology of brain abscess [98]. Among other subjects he wrote about were cholera, steatorrhoea caused by intestinal lymphoma, rheumatic fever, anorexia nervosa, and paraplegia.

\section{Spinal Cord and Paraplegia}

Gull's interest in the segmentation of the cord was shown in his Goulstonian lectures of 1848 . He divided paraplegia into three groups: spinal, peripheral, and encephalic. The peripheral group can be interpreted as mainly polyneuropathies with predominant sensory loss. The encephalic group comprised partial paralyses often with transient cerebral symptoms, possibly ischaemic; some may have been syphilitic (see Spillane [10]). The spinal group was dominated by motor paralysis with both anteriorly and posteriorly sited lesions.

His main work on paraplegia, published between 1856 and 1858, was original and along with Brown Séquard first placed the clinical features in context with the prevailing, limited understanding of spinal cord pathology, for the first time. Based on his series of 32 cases with autopsies in 29 instances he portrayed the clinicopathological correlates. But nothing was more difficult than 'the determination at the bedside, of the causes'. Pathologically softening and inflammation were sometimes evident, but in many instances no obvious aetiology was found. One might have to seek for 'atomical' as distin-

\footnotetext{
A similar success in Lisbon reported in 1890 [5] was reported in Portuguese and was overlooked.
} 
guished from 'anatomical' causes, he speculated. He described two types of partial lesions, one confined to a segment of the cord, the other extending longitudinally in one of its columns. He noticed and was puzzled by degenerations of the posterior columns that could cause an 'inability to regulate motor power'.

Gull recognised girdle pain as seldom absent from extrinsic compression, often signifying meningeal involvement. Paralysis of the lower extremities could, he thought, be consequent upon diseases of the bladder and kidneys ('urinary paraplegia'). The bladder infection was the source of inflammatory phlebitis extending from pelvic to spinal veins.

Meningitis with myelitis was found and attributed to exposure to cold or fatigue.

In 5 traumatic cases, the vertebral column was often but not invariably fractured and could compress the cord. $\mathrm{He}$ recorded one instance in a 33-year-old woman of a thoracic disk prolapse compressing the cord, without evident trauma. Tumours also figured in 7 of his 32 patients; 2 were metastatic from kidney and lung. Two had intramedullary cervical tumours, and 1, a Guy's nurse, probably had a cystic astrocytoma.

Robert Bentley Todd (1847), Ernest Horn, and Moritz Romberg (1851) before him had described tabes dorsalis [11] and noted atrophy of the cord, but in an important paper, Gull also stressed the involvement of the posterior column in paraplegia with sensory ataxia [12].

\section{Anorexia Nervosa}

Louis-Victor Marce (1828-1864) described a patient with anorexia nervosa in 1859 , but Richard Morton is generally credited with the first medical description of anorexia nervosa in 1689 [13]. Gull wrote the seminal work and provided its name. His first account was in 1868:

\footnotetext{
'At present our diagnosis is mostly one of inference, from our knowledge of the liability of the several organs to particular lesions; thus we avoid the error of supposing the presence of mesenteric disease in young women emaciated to the last degree through hysteric apepsia, by our knowledge of the latter affection, and by the absence of tubercular disease elsewhere [14].'
}

Six years later he published a more comprehensive description:

'In ... 1868, I referred to a peculiar form of disease occurring mostly in young women, and characterized by extreme emaciation ... At present our diagnosis of this affection is negative, so far as determining any positive cause from which it springs ... The subjects ... are ... chiefly between the ages of sixteen and twenty- three ... My experience supplies at least one instance of a fatal termination ... Death apparently followed from the starvation alone ... The want of appetite is, I believe, due to a morbid mental state ... We might call the state hysterical [15].

Here, he establishes its name and in keeping with then current ideas asserted a hysterical cause.

\section{Teachings and Aphorisms}

A highly successful and clinically astute physician, Gull debunked much empirical and irrational therapeutics, but effectively taught how much more important was the patient than the illness he suffered. He described himself as 'a clinical physician or nothing.' Gull believed in minimal use of drugs and defended the moderate use of vivisection and clinical investigation. He taught, 'The road to a clinic goes through the pathologic museum and not through the apothecary's shop'. This generous (holistic) attitude was focussed on his patients as people: 'Never forget that it is not a pneumonia, but a pneumonic man who is your patient. Not a typhoid fever, but a typhoid man' [1].To one hypochondriac he said, 'You are a healthy man out of health.' This pleased the patient so much he wanted to know why the other doctors had not told him.

In 1887 , he sustained and recovered from a stroke but had recurrences, the final one proving fatal. He died at 74 Brook Street on January 29th, 1890, and was buried at Thorpe-Le-Soken. By his will with a codicil dated November 27th, 1888, he left GBP 344,022 19s. 7d. His death certificate was signed by his son-in-law, Theodore Dyke-Acland, whose wife (Gull's daughter) benefited by GBP 26,000 (The Times, March 21st, 1890).

\section{Honours}

Gull was created a baronet in 1872 when he treated the Prince of Wales for typhoid. His enhanced reputation was said to have made him wealthier than any English physician before him. Many distinctions were bestowed upon him. He was made a DCL of Oxford in 1868, a Fellow of the Royal Society in 1869, LLD of Cambridge in 1880 and of Edinburgh in 1884. He was a Crown member of the General Medical Council from 1871 to 1883, and representative of the University of London in the Council from 1886 until his illness in the following year. In 1887, he became personal physician to the Queen, but after his stroke in 1888 , he closed his practice. 


\section{Conspiracy Theories}

Gossip at Thorpe-Le-Soken (his childhood home) alleged that Gull did not die as officially stated. His funeral was called a sham, and he was buried at night, several years later. There was a crazed but popular rumour that Sir William Gull was the notorious serial killer Jack the Ripper, who terrorised the East End of London by violently murdering prostitutes [16] during 1888, despite the fact that he was elderly and had sustained a stroke. Coercion from the Prime Minister, stemming from the monarch was supposed to have persuaded him to kill those said to be involved in unsavoury incidents embarrassing to the throne [16]. Based partly on a discredited book (The
Final Solution by Stephen Knight), a highly successful television film emerged in 1988 - produced by David Wickes, with Ray McAnally as Sir William Gull, and Michael Caine as Chief Inspector Frederick Abberline. There is scant evidence to support this far-fetched tale [17] and most historians have dismissed it.

More fitting is an inscription to his memory on the tablet in the Chapel at Guy's Hospital which describes

'[His] instinctive insight, unwearied patience, exact method, ready resources, and above all hearty sympathy. Each and all of these brought their influence to bear on his work and on his life, and made them what they were.'

\section{References}

1 Acland TD: William Withey Gull - A Biographical Sketch. London, Adlard \& son.1896. (See full text at http://www.casebook.org/ press_reports/times/18900130.html)

2 The Times, 30 January 1890.

3 Gull WW: On a cretinoid state supervening in adult life in women. Trans Clin Soc Lond 1873/1874; 7:180-185.

4 Ord WM: Report of a committee of the Clinical Society of London nominated December 14, 1883 , to investigate the subject of myxoedema. Trans Clin Soc Lond 1888;21(suppl).

5 Bettencourt AM, Serrano JA: Un cas de myxoedème traité par la greffe hypodermique du corps thyroïde d'un mouton. Sem Med 1890; 10:294.

6 Murray GR: Note on the treatment of myxoedema by hypodermic injections of an extract of the thyroid gland of a sheep. Br Med J 1891; $2: 796$
7 Gull WW, Sutton HG: On the pathology of the morbid state commonly called chronic Bright's disease with contracted kidney ('arterio-capillary fibrosis'). Med Chir Trans Lond 1872;55: 273-326.

8 Gull WW: Case of progressive atrophy of the muscles of the hands: enlargement of the ventricle of the cord in the cervical region, with atrophy of the gray matter. Guy's Hosp Rep 1862;8:244-250.

9 Russell, J: Abscess of brain; in John Russell Reynolds's System of Medicine London. Macmillan, vol 1 \& 2, 1866/1868.

10 Spillane JD: The flowering of neurology, in Spillane JD: Doctrine of the Nerves. Oxford, Oxford University Press, 1981, pp 322-324.

11 Pearce JMS: Romberg and his sign. Eur Neurol 2005;53:210-213.
12 Gull WW: Cases of paraplegia (with autopsies of ataxic cases, showing lesions in the posterior columns of the spinal cord). Guy's Hosp Rep 1856;2:143-190; 1858;4:169-216.

13 Pearce JMS: Richard Morton: origins of anorexia nervosa. Eur Neurol. 2004;52:191192.

14 Gull WW: Address in medicine delivered before the Annual Meeting of the British Medical Association at Oxford. Lancet 1868;ii:171176.

15 Gull WW: Anorexia nervosa (apepsia hysterica, anorexia hysterica). Trans Clin Soc Lond 1874; 7:22-28.

16 Knight S: Jack the Ripper: The Final Solution. London, Grafton, 1985.

17 Sugden P: The Complete History of Jack the Ripper. New York, Caroll \& Graf, 1994. 